\title{
Os fatores predominantes na escolha pelos cursos de Bacharelado Interdisciplinar da Universidade Federal da Bahia
}

\author{
The predominant factors in choosing the Interdisciplinary Bachelor courses of \\ Federal University of Bahia
}

\section{Los factores que predominan en la elección de los Bachilleratos Interdisciplinarios de la Universidad Federal de Bahía/Brasil}

\author{
CAROLINnE MONTES BAPTISTA VieIRA* \\ RENATA MEIRA VERAS**
}

\begin{abstract}
RESUMO
Esse artigo tem como objetivo investigar sobre os fatores predominantes na escolha dos estudantes pelos Bacharelados Interdisciplinares (BI) da Universidade Federal da Bahia (UFBA). Para isso foi realizada uma pesquisa qualitativa exploratória que teve por objetivos investigar se a escolha pelos BI implicava em uma busca vocacional e identificar quais fatores motivaram e influenciaram a escolha pelos cursos. Os resultados dos estudos demonstraram a presença de uma indecisão vocacional/profissional nos estudantes dos Bacharelados Interdisciplinares, bem como um conhecimento mais informal sobre os BI ao ingressar. Por outro lado, muitos entrevistados indicaram interesse prévio nos cursos de progressão linear que caracterizam os de segundo ciclo. Portanto, esse estudo pode contribuir para o fortalecimento e crescimento do modelo de ciclos proposto com a criação dos BI na UFBA, já que mostra sua importância em oferecer uma formação mais ampla, interdisciplinar e oportunizar um tempo maior para escolha vocacional/profissional, o que pode contribuir para uma maior maturidade nesta escolha.
\end{abstract}

Palavras-chave: Bacharelados Interdisciplinares. Escolha vocacional/profissional. Universidade Federal da Bahia.

\begin{abstract}
This article aims to describe the research on the prevailing factors in students' choice for Interdisciplinary Bachelors (BI) of the Federal University of Bahia (UFBA). For this study it was made an exploratory qualitative research that aimed to investigate if the choice for BI involved in a vocational pursuit and identify what factors motivated and influenced the choice for the courses. The study results showed the presence of a vocational/career indecision in students of Interdisciplinary Bachelors, as well as a more informal knowledge about the BI when joining in. On the other hand, the interviewed students indicated a prior interest in professional courses. Therefore this study may contribute to the strengthening and growth of cycles model purposed by BI at UFBA, since it shows its importance in offering a broader, interdisciplinary training and providing more time to vocational/career choice, which can contribute to more maturity in this choice.
\end{abstract}

Keywords: Interdisciplinary Bachelors. Vocational/career choice. Federal University of Bahia.

\section{RESUMEN}

El presente artículo tiene por objetivo investigar los factores que predominan en la elección de los Bachilleratos Interdisciplinarios (BI) de la Universidad Federal de Bahía/Brasil (UFBA) por parte de los estudiantes. En el marco de una investigación cualitativa exploratoria se buscó identificar los factores que motivaron e influenciaron la elección de los alumnos, detectando implicaciones relacionadas a la búsqueda vocacional. Los resultados demuestran el conocimiento informal sobre los BI así como también la indecisión vocacional/profesional de los alumnos ingresantes. Por otro lado muchos de los entrevistados manifestaron su previo interés por los cursos de progresión lineal que caracterizan a los del segundo ciclo. Por lo tanto esta investigación puede contribuir para el fortalecimiento y crecimiento del modelo de ciclos propuesto al ser creados los BI en la UFBA ya que, además de ofrecer una formación más amplia e interdisciplinaria, demuestra la importancia de favorecer elecciones vocacionales/ profesionales maduras, prolongando el período de tiempo necesario para la elección.

Palabras clave: Bachilleratos Interdisciplinarios. Elección vocacional/profesional. Universidad Federal de Bahía.

* Psicóloga. Mestre em Estudos Interdisciplinares sobre a Universidade pelo Programa de Pós-Graduação Estudos Interdisciplinares sobre a Universidade (PPGEISU-UFBA). Universidade Federal da Bahia.E-mail: < carobap@gmail.com>.

**Doutora em Psicologia pela Universidade Federal do Rio Grande do Norte. Professora Adjunto do Instituto de Humanidades, Artes e Ciências Prof. Milton Santos da Universidade Federal da Bahia. Docente permanente do Programa de Pós-Graduação Estudos Interdisciplinares sobre a Universidade (PPGEISU-UFBA).E-mail: <renata.veras@ufba.br>. 


\section{INTRODUÇão}

No decorrer da vida, o ser humano realiza uma série de escolhas, dentre elas está a escolha vocacional/ profissional, que geralmente ocorre na juventude, quando o sujeito está passando por uma série de transformações físicas, psicológicas e sociais de forma muito intensa e acelerada. Além destas transformações existem algumas pressões que vêm da família, do grupo de amigos, da mídia, da sociedade, que interferem bastante no bem estar do jovem, na sua capacidade de discernimento e consequentemente em suas escolhas.

Segundo Bohoslavsky (2003), a adolescência caracteriza-se como uma etapa do ciclo vital, onde a pessoa passa por momentos de desestruturação e reestruturação de seu mundo interior e exterior. Nesse sentido, Bock (2001) e Müller (1988) retratam esta etapa como um período de crise, onde o jovem pode se comportar de maneira instável, desobediente, desafiadora e gerar conflitos sociais e familiares, sendo que fazer uma escolha nesse período é uma tarefa difícil.

No entanto, justamente nessa época, ele é convocado a eleger uma profissão que o acompanhará por boa parte de sua vida, normalmente sem dispor de uma educação direcionada ao encontro da sua vocação desde criança, o que torna suas escolhas e seu projeto de vida um tanto quanto arriscados, pois ainda não possui a maturidade psicológica e vivencial necessárias para uma tomada de decisão consciente.

Segundo Bardagi, Lassance e Paradiso (2003), o conhecimento transmitido na escola e na família ao longo da educação têm sido falho no que diz respeito à tomada de decisões e oportunidades para o desenvolvimento vocacional. Nesse aspecto, Müller (1988) coloca que a escola não ensina a escolher, a pensar, a resolver problemas, a refletir sobre as realidades: social, cultural, histórica e profissional e quando o faz ainda é de forma ocasional e desarticulada.

Contudo, no ensino médio, o jovem pode ter tido contato com algum processo de orientação vocacional/ profissional no colégio ou procurar esse serviço por iniciativa própria ou da família, mas essa prática ainda é pouco comum, principalmente entre os oriundos de classes populares. Paradiso e Sarriera (2009) ressaltam que é necessário ampliar o conhecimento a respeito desta população sob a perspectiva do desenvolvimento de carreira, embora existam trabalhos brasileiros e pesquisa com jovens dessas classes.

Quanto à vocação, Rivelis (2011) a define como a possibilidade de o ser humano encontrar seus dons e desenvolvê-los com a ação cotidiana, aprendendo a usá-los em benefício de todos. O autor Isasa (2010) complementa essa ideia ao colocar que a manifestação da vocação pode se dar através do exercício de uma profissão, ocupação, ação ou hobby, configurando um estilo de vida.

A escolha vocacional/profissional é uma questão fundamental no momento da entrada na universidade, onde o jovem tem de optar qual curso vai querer seguir e começa a definir qual carreira almeja construir. Tanto é que, segundo Macedo (1998), a temática da carreira profissional tem sido amplamente abordada nos últimos anos, pois novos cargos e novas oportunidades de trabalho começam a surgir em um ritmo bastante acelerado, acompanhados das questões da globalização e dos avanços tecnológicos. Isso faz planejar e repensar as formações profissionais e ocupacionais, bem como as carreiras, de acordo as necessidades do mercado de trabalho articuladas às preferências pessoais.

De acordo aos Anais da Conferência Mundial sobre o Ensino Superior, realizada pela UNESCO em 1999, o mercado de trabalho tem exigido das universidades a formação de profissionais com as características: flexibilidade, inovação, criatividade, pré-disposição a aprendizagem constante, capacidade de enfrentar incertezas, aptidão para a comunicação, habilidade com trabalho em equipe, espírito empreendedor, familiaridade com culturas diversas, competências genéricas em vários campos do conhecimento, principalmente nas novas tecnologias, que formam as bases das várias competências profissionais (UFBA, 2008).

Para dar conta de formar profissionais com essas competências, a universidade brasileira precisa se reestruturar, rever seu modelo de ensino. Uma reforma na educação brasileira é necessária, como já debatiam os autores Anísio Teixeira, Fernando de Azevedo, Lourenço Filho, Darcy Ribeiro, Florestan Fernandes e Naomar de Almeida Filho. Nessa direção, foi criado em 2006, na Universidade Federal do ABC (UFABC) em São Paulo, um novo modelo de educação superior composto por ciclos, que culminou na implantação do Bacharelado em Ciência e Tecnologia. Este modelo foi inspirado no sistema de educação atual da Europa, vigente a partir do Processo de Bolonha ${ }^{1}$, juntamente com o movimento da Escola Nova, idealizado por Anísio Teixeira na década de 1960. Porém, incorpora um desenho inovador, necessário para responder às atuais demandas de formação acadêmica (CAMARGO et al., 2010).

Também inspirados nas mesmas ideias, foram criados na Universidade Federal da Bahia (UFBA) os Bacharelados Interdisciplinares (BI) em 2009, a partir do projeto UFBA Nova em 2007, que surgia

\footnotetext{
A Declaração de Bolonha trata-se de um documento assinado por ministros da educação de países europeus em 19/06/1999, que estabelece um sistema de créditos transferíveis e acumuláveis, homogêneos para vários países, com três ciclos, sendo o primeiro básico e uniforme de três anos (LIMA; AZEVEDO; CATANI, 2008).
} 
concomitantemente com o Programa de Reestruturação e Expansão das Universidades Federais Brasileiras (REUNI).

Dentro dessa proposta, os BI são uma nova modalidade de cursos universitários que englobam uma formação geral humanística, científica e artística, promovendo uma reforma curricular. Eles estão estruturados de forma a compor o primeiro ciclo da formação acadêmica, onde posteriormente, nos ciclos sequentes, o estudante poderá seguir uma formação profissional ou de pós-graduação. O modelo de formação em ciclos já é realidade no ensino superior norte-americano e europeu.

De acordo ao projeto pedagógico (UFBA, 2008), os BI são ofertados em quatro modalidades, de acordo as grandes áreas do conhecimento - Artes, Ciências e Tecnologias, Humanidades, Saúde. Cada modalidade serve como pré-requisito para progressão aos ciclos seguintes e constitui uma formação com terminalidade própria, ou seja, após o seu fim o estudante recebe um diploma de bacharel. A duração total dos BI prevista é de 3 anos, com a carga horária de 2400 horas.

Os BI almejavam uma transformação curricular e pedagógica do ensino, que desse conta do esgotamento do modelo de graduação profissionalizante e seus principais impactos, como, por exemplo, o alto índice de evasão universitário e defasagem das metodologias e estratégias pedagógicas (VERAS; LEMOS; MACEDO, 2015).

Uma das vantagens ao cursar os BI, além da nova estrutura curricular que vai de encontro às transformações ocorridas nas últimas décadas, é a possibilidade de esperar um tempo maior para amadurecer a escolha profissional, já que o estudante ingressa na universidade e tem um período de três anos para se adaptar à vida universitária, conhecer as diversas áreas do conhecimento e profissões, para então, se assim o quiser, escolher uma profissão (UFBA, 2008).

Essa nova modalidade de ingresso na Universidade Federal da Bahia motivou a elaboração desse estudo, que teve como objetivo geral investigar os fatores predominantes na escolha dos alunos pelos Bacharelados Interdisciplinares de acordo com suas áreas: Saúde, Humanidades, Ciências e Tecnologia e Artes.

\section{MÉTodo}

Para a investigação dos fatores predominantes na escolha dos estudantes ingressos pelos Bacharelados Interdisciplinares da UFBA, foi utilizada a metodologia de pesquisa qualitativa através da aplicação de entrevistas semiestruturadas e grupos focais. Sendo assim, as entrevistas em profundidade foram realizadas com 23 estudantes ingressos nos Bacharelados Interdisciplinares da UFBA em 2014.1, sendo 7 do BI de Saúde, 6 do BI de Humanidades, 5 do BI de Artes e 5 do BI de Ciência e Tecnologia. Esses estudantes foram abordados no momento da sua matrícula no BI e convidados pelo pesquisador a participarem da entrevista por alguns minutos. Após a aceitação do convite, foi entregue aos entrevistados o Termo de Consentimento Livre e Esclarecido (TCLE), para que tivessem o conhecimento de que se tratava a pesquisa, bem como sobre as suas implicações éticas, de acordo com a Resolução de Pesquisa com seres humanos (Resolução 196/96).

Foram realizados também 3 grupos focais, contendo estudantes das várias modalidades de $\mathrm{BI}$ e de variados semestres, ou seja, grupos heterogêneos, sendo 2 grupos com 4 participantes e 1 grupo com 9 . O total de entrevistados nos grupos focais foi de 7 no BI de Saúde, 4 no BI de Humanidades, 3 no BI de Artes e 3 no BI de Ciência e Tecnologia. Os participantes foram convidados em sala de aula a participar da pesquisa, após o término de sua aula, sendo solicitado voluntários de cada BI. Para isso, o pesquisador foi nas salas em que estavam acontecendo as aulas dos componentes obrigatórios do BI, comuns às quatro modalidades do Bacharelado Interdisciplinar. Assim como nas entrevistas em profundidade, também foi entregue aos participantes o TCLE.

Assim, ao todo na pesquisa, foram entrevistados 40 estudantes, sendo 14 do BI em Saúde, 10 do BI em Humanidades, 8 do BI em Artes e 8 do BI em Ciência e Tecnologia.

Os critérios para participação da pesquisa foram: alunos regularmente matriculados em um Bacharelado Interdisciplinar e que estivessem cursando os três primeiros semestres, período em que o aluno cursa todos os componentes curriculares obrigatórios do IHAC.

Após a coleta realizada nas entrevistas em profundidade e nos grupos focais, os dados foram transcritos e submetidos à análise de discurso. A análise do discurso de Willig (2001) e Phillips e Hardy (2002) são abordagens que consideram o cotidiano como "discursivamente organizado", enfatizando o papel da linguagem na organização das ideias, representações e do universo simbólico presente nas relações interpessoais e institucionais. Essa forma de análise permite também verificar como o poder é reproduzido e legitimado pela fala e pelos textos dos grupos dominantes ou instituições (VÉRAS, 2010). Para a discussão dos dados, os entrevistados foram identificados com nomes de flores, para preservar o sigilo sobre sua identidade.

\section{Resultados e Discussão}

A partir da análise dos dados coletados na pesquisa, foram construídas a categorias e as subcategorias temáticas para ilustrar os fatores predominantes na escolha pelos BI, 
como mostra a Tabela 1. Após categorização dos dados coletados, estes foram analisados de acordo a literatura que fundamenta a pesquisa.

Tabela 1. Categorias e subcategorias

\begin{tabular}{ll}
\hline \multicolumn{1}{c}{ Categorias } & \multicolumn{1}{c}{ Subcategorias } \\
\hline Motivos da escolha & A. Ingressar em um curso de CPL; \\
pelos BI & B. Interdisciplinaridade; \\
& C. Indecisão quanto a escolha profissional. \\
\hline
\end{tabular}

\section{Motivos da escolha pelos BI}

Essa categoria identifica os motivos que levaram os estudantes pesquisados a escolherem os cursos de Bacharelado Interdisciplinar da UFBA, uma modalidade recente de graduação, com características interdisciplinares e de formação geral. Observou-se nos relatos das entrevistas que os motivos alegados para a escolha desses cursos foram a possibilidade de ingressar em um curso de CPL após a sua conclusão, a amplitude e variedade de conteúdos que os Bacharelados Interdisciplinares oferecem nas diferentes áreas do conhecimento, a interdisciplinaridade, o que enriquece a formação e permite realizar uma escolha vocacional/profissional mais segura e efetiva. Outro motivo colocado foi a questão da indecisão quanto à escolha profissional. Alguns alegaram estar indecisos quanto à escolha e por isso escolheram fazer o BI. A partir desses motivos, foram criadas as subcategorias: A. Ingressar em um curso de CPL; B. Interdisciplinaridade; C. Indecisão quanto a escolha profissional.

\section{A. Ingressar em um curso de CPL}

Dos estudantes que alegaram como principal motivo de escolha pelos Bacharelados Interdisciplinares a possibilidade de ingresso em um curso de progressão linear (CPL), após a sua conclusão, houve um destaque nos estudantes do BI em Saúde, com relação à opção pelo curso de Medicina, os quais declararam ter escolhido fazer BI como uma alternativa para ingressar no curso de Medicina, como mostram as falas:

"Eu passei três anos no curso pré-vestibular, prestei vestibular para três áreas, humanística, exatas e biológicas, mas o que eu vi que eu tinha mesmo afinidade era com a parte biológica, então eu escolhi Medicina, como eu não passei, acabei entrando no BI, como uma alternativa para entrar em Medicina." (Cravo)

"Eu sempre quis, tive o sonho de fazer Medicina, fiz um curso preparatório durante dois anos. Quando saí do ensino médio, e aí, eu não conhecia o BI, meus amigos falaram que tinha a oportunidade de cursar Medicina pelo BI, aí fui ver o SISU, minha nota entrava e aí eu acabar entrando..." (Antúrio)
“(...) quando eu entrei no BI, quando botei lá no ENEM, BI de saúde, eu queria porque me falaram que eu tinha como fazer Medicina, pelo BI de Saúde (...)." (Lírio)

"Escolhi com o intuito de migrar para Medicina após o término do curso." (Cravina)

\begin{abstract}
"Eu usei sim o BI como um trampolin para Medicina, quando eu entrei eu pensei em Medicina pelo fato do retorno financeiro que o curso poderia me proporcionar, não pelo ah eu tenho amor... não! Não por amor, mas pelo retorno financeiro que eu poderia ter com o curso. Não tenho aptidão, não tenho nada... eu só gosto da área de saúde, eu gosto de estudar saúde coletiva, por exemplo (...)." (Ciclame)
\end{abstract}

Fica claro nessas falas que os estudantes viram no BI um caminho para contornar as dificuldades de ingresso em Medicina, um curso altamente concorrido e que exige notas altas no Enem. $\mathrm{O}$ estudante Ciclame deixa isso bem claro e acrescenta que o interesse pelo curso de Medicina é meramente econômico. Assim como ele, Centáurea também afirma o mesmo:

“(...) eu entrei pensando no BI de Saúde, pensando em fazer Medicina (...) eu já entrei com esse pensamento: 'Vou fazer BI de Saúde, pra entrar em Medicina e ganhar dinheiro, e depois eu faço Jornalismo se eu quiser...'." (Centáurea)

Sobre a passagem do BI em Saúde para os cursos de CPL, dos 127 estudantes que graduaram em 2013, 65 migraram para Medicina, ou seja, um pouco mais que a metade (ANDRADE, 2014).

A estudante Begônia coloca que optou pelo BI em Saúde para ter um tempo de preparar a família para dizer que o seu desejo não é fazer Medicina:

"Eu entrei no BI de saúde, na verdade porque, minha família toda achava que eu ia fazer Medicina, por causa da minha família de médicos, e eu sempre quis fazer Veterinária, aí eu fiz o BI pra poder dar um tempo, pra amaciar a galera e avisar que eu não vou ser médica. Aí eu entrei no BI de saúde (...).” (Begónia)

Mesmo os que alegaram indecisão quanto à escolha, a Medicina estava presente como um dos cursos almejados, como mostram os relatos:

"Na verdade, é, eu tive indecisão, eu fiquei entre Medicina e Biofísica, e aí eu tinha passado em Biofísica, só que não é aqui em Salvador e aí eu preferi pelo BI mesmo, foi mais pela indecisão mesmo e também porque minha nota não dava pra Medicina, aí eu falei, não BI que é um caminho a mais, que eu possa estar percorrendo.” (Celósia) 
“(...) escolhi o BI mais por uma indecisão, de não saber realmente o que eu quero ser como profissional. Eu fiz vestibular para Biologia, pra Medicina, pra Biotecnologia, então eu tava com muita dúvida em relação a qual CPL eu, e, mas eu sabia a minha área, eu sabia que era área da saúde, mas ainda não sei qual CPL quero (...)." (Hortência)

Este mesmo estudante (Hortência), quando indagado sobre o que entendia por vocação, respondeu:

\begin{abstract}
“Acho que é aptidão, vontade de fazer algo, de estar presente, eu mesmo, eu penso em Medicina e quando eu vejo sei lá, eu vejo o médico sem fronteiras, eu vejo, sei lá, pessoas indo cuidar de crianças, de idosos, sabe só, simplesmente pelo fato de estar cuidando, de estar ajudando, isso me faz pensar em Medicina, eu acho que vocação pode ser isso, isso de querer fazer algo por aquilo (...)." (Hortência)
\end{abstract}

Isso leva a questionar se de repente não havia a intenção já definida desses jovens em cursar Medicina após o BI, mas podem ter tido receio de falar, talvez por medo de críticas, já que existe o chavão de que "o BI em Saúde está sendo utilizado como um trampolim para entrar em Medicina." Pode ter ocorrido também a intensão de esconder a escolha, pela alta competitividade que existe em obter escores elevados como requisito de seleção no BI em Saúde para ingressar em Medicina e não revelar sua intensão aos colegas no momento dos grupos focais.

Depoimentos escritos por alunos dos BI, ao longo dos dois semestres do componente curricular Estudos da Contemporaneidade I e II, em 2009, mostraram que a opção pelos BI muitas vezes é uma forma de driblar as dificuldades impostas pela acirrada concorrência do vestibular, exame ainda vigente nesse período (MAZONI; CUSTÓDIO; SAMPAIO, 2011).

Destaca-se que, em 2010, o vestibular foi substituído pelo Enem (MAZONI; CUSTÓDIO; SAMPAIO, 2011), e em 2014 a UFBA toda aderiu ao Sisu, o que permite que a nota obtida no Enem seja utilizada para ingressar em qualquer curso, não só na UFBA, mas em qualquer universidade pública que tenha aderido ao Sisu. O candidato, ao efetuar sua inscrição nesse sistema, deve escolher, por ordem de preferência, até duas opções entre as vagas ofertadas pelas instituições que aderiram a ele. Normalmente os estudantes têm escolhido os cursos de CPL como primeira opção e os bacharelados interdisciplinares na UFBA como segunda opção, como uma chance a mais de ingressar na universidade e chegar até o curso almejado, como mostra a fala dos estudantes:

“(...) A minha primeira opção foi Direito, mas por conta da nota de corte eu escolhi o BI." (Aquilégia, BI em Humanidades)

\begin{abstract}
“(...) eu botei como 2aㅗ opção o BI, pra caso eu não conseguisse arquitetura, eu fazia o BI e ingressava para arquitetura dentro do BI." (Camélia, BI em C e T)

“Então, eu à princípio queria fazer Direito, só que eu tinha o BI como $2^{\underline{a}}$ opção, não como um refúgio, mas mais como uma 2a opção mesmo (...).” (Amarílis, BI em Humanidades)
\end{abstract}

Os estudantes do BI em Humanidades, assim como os do BI em Saúde, também revelaram interesse em ingressar em um curso de CPL específico, após a conclusão do BI, que é o curso de Direito, como se verifica nas falas dos estudantes:

\begin{abstract}
"Na verdade, como a UFBA agora é SISU né, eu coloquei minha nota e esperei ser chamada, porque o curso que eu quero mesmo é Direito, só que minha nota não chegou a nota de Direito, então eu coloquei no BI, pra daqui a um ano e meio lá, sabe, com minhas notas eu posso passar pra o curso que eu quero (...)." (Azaleia)

"Foi aquele jogo do SISU, né... e de repente o BI se apresentou pra mim como uma possibilidade de, uma possibilidade real de eu fazer Direito (...) a minha primeira opção foi Direito, por conta da nota de corte eu escolhi o BI de Humanidades." (Aquilégia)

“Então, eu a princípio queria fazer Direito, só que eu tinha o BI como $2^{\underline{a}}$ opção, não como um refúgio, mas mais como uma $2^{\mathrm{a}}$ opção mesmo, porque pelo pouco que eu ouvia falar e até as pessoas que me diziam que conheciam pessoa que faziam, diziam que essas pessoas gostavam muito, que a experiência era muito boa (...)." (Amarílis)
\end{abstract}

Por outro lado, os relatos dos alunos também indicaram que alguns se demonstram indecisos, apesar de pensar em Direito:

"Eu à princípio, queria fazer Direito (...) Eu pretendo concluir o BI e ingressar em outra área que eu não sei se até o final vou continuar querendo Direito." (Amarílis)

"Na verdade, a minha indecisão é um dos motivos que escolhi o BI. Eu não tenho certeza do curso que eu acho que tenho afinidade, que é Direito (...)." (Áster)

“Antes eu queria Direito, já estava meio que decidida nisso, só que eu tenho um professor de geografia, que no primeiro dia de aula, no $3^{\circ}$ ano, ele já chegou falando sobre o BI (...) e como eu tenho interesse em humanidades, eu achei uma proposta boa que era eu ter acesso a várias matérias da área de humanas e até poder ter certeza né, não sei foi mais por isso.” (Beladona)

“(...) Eu acho que eu quero Direito, mas eu tô me deixando levar pelo próprio $\mathrm{BI}$, porque ele te dá oportunidade de você pegar matérias (...).” (Íris azul) 
Nesses discursos pode estar oculto o mesmo receio que os estudantes do BI em Saúde podem ter tido em revelar sua decisão de fazer Medicina. Da mesma forma, os estudantes de Direito podem estar com inquietações semelhantes, devido a alta concorrência do curso de Direito e a exigência de altos escores para ingressar no curso após a conclusão do BI.

Em 2013, dos 213 estudantes graduados no BI em Humanidades, 120 ingressaram no CPL em Direito (ANDRADE, 2014), o que mostra o forte interesse dos estudantes por esse curso.

Mas e agora com o Sisu? Os estudantes continuam vendo no BI uma alternativa para driblar a concorrência na entrada em cursos socialmente privilegiados, como é o caso de Medicina e Direito? E se o veem assim, haveria algum problema?

Afinal, como coloca Almeida Filho (2010) o acesso à universidade costuma ser visto como um fator fundamental para a redução das desigualdades de renda e melhoria na qualidade de vida em sentido amplo. Segundo o autor, o padrão de seleção instituído até então, o vestibular, privilegiava candidatos com maior capital econômico e cultural, que ocupavam cursos de maior prestígio social e que formavam uma elite econômica e culturalmente privilegiada. No entanto, essa realidade tem mudado. Os dados do Instituto Nacional de Estudos e Pesquisas Educacionais Anísio Teixeira (Inep), a partir de pesquisa realizada em 2011, mostram que, nos jovens de 18 a 24 anos, evolui quase 10 vezes a presença dos $20 \%$ de menor renda na universidade: de 0,5\% em 1997 para $4,2 \%$ em 2011, enquanto que os $20 \%$ de maior rendimento cresceram em menor ritmo: de $22,9 \%$ para $47,1 \%$, pouco mais que o dobro (SAMPAIO, et.al, 2013).

Já nos Bacharelados Interdisciplinares em Ciência e Tecnologia e em Artes, não foi identificado como motivo de escolha pelos BI o interesse em um curso de CPL com representatividade específica, como no caso dos BI de Saúde e Humanidades os cursos de Medicina e Direito, respectivamente, mas alguns declararam que o motivo da escolha pelo BI foi ver nele um caminho para ingressar no CPL que estavam interessados, como mostra algumas falas:

"Eu queria fazer Arquitetura, só que a média do ENEM foi muito alta, e (...) aí eu botei como segunda opção o $\mathrm{BI}$, pra caso eu não conseguisse Arquitetura, eu fazia o BI e ingressava para Arquitetura dentro do BI (...)." (Camélia, BI em Ciência e Tecnologia)

"Na verdade eu não conheço muito sobre o BI, eu queria fazer Engenharia Mecânica e eu sei que o BI de C e T é ligado nessa área, então eu optei pelo BI (...)." (Acácia, BI em Ciência e Tecnologia)

"Eu tenho interesse em fazer um CPL, eu acho que Artes Plásticas ou Designer (...).” (Amaranto, BI em Artes)
“(...) Durante a seleção do SISU não havia a possibilidade de eu escolher o curso de Designer de Interiores, então eu entrei no site da UFBA e fui ler o que era o BI de Artes pra ter certeza que através dele eu chegaria ao Designer de Interiores." (Agerato, BI em Artes)

“(...) Eu fiquei decidido por teatro (...) eu tenho a oportunidade de ir pra um outro curso caso eu mude de ideia e dentro daquele espaço, talvez eu fique pegando matérias mais desenvolvidas pro teatro, e fique um pouco mais preparado pra seguir esse curso depois se for mesmo o que eu queira.” (Lisianto, BI em Artes)

Quanto ao ingresso em cursos de CPL, dos 89 estudantes diplomados no BI em Artes em 2013, 42 ingressaram em cursos de CPL variados, um pouco menos que a metade.

Já no BI de Ciência e Tecnologia, dos 66 diplomados, 63 ingressaram em cursos de CPL variados.

A partir dos relatos, observa-se que há um interesse dos estudantes dos BI em Artes e Ciência e Tecnologia para cursar um CPL após concluir o BI, mas em cursos variados, o que pode estar indicando que nessas duas modalidades de Bacharelado Interdisciplinar, o BI não é utilizado como uma alternativa de ingresso em cursos de graduação mais concorridos e privilegiados socialmente.

\section{B. Interdisciplinaridade}

Outro motivo alegado pelos estudantes na escolha pelos Bacharelados Interdisciplinares foi a amplitude e variedade de conteúdos que esses cursos oferecem nas diferentes áreas do conhecimento, a interdisciplinaridade, que segundo eles permite cursar matérias de áreas diversas, ter uma formação mais abrangente, como ilustram as falas:

“(...) o BI possibilita que você aborde mais áreas do conhecimento, e traga isso pra você, eu posso cursar matérias de belas artes, filosofia, ciências sócias, isso amplia, querendo ou não, a minha bagagem para o futuro curso ou profissão." (Cerejeira, BI em Ciência e Tecnologia)

"Eu gostei da ideia de interdisciplinaridade mesmo (...) eu acho que o BI reúne um pouquinho de cada coisa que eu gosto, sem contar que eu acho que as artes se comunicam entre si, eu acho que para você ser, acho que você precisa de referência, eu acho que um artista plástico ele precisa ter referência de tantas outras coisas ligadas a arte, ligadas ao mundo mesmo, e o BI oferece isso, tem essa proposta." (Amaranto, BI em Artes)

“(...) Eu poder ter a possibilidade, assim, de tá conhecendo, não ficar restrita só a uma área, entendeu? Eu acho que o BI, pelo pouco que eu ouço falar dele, te dá a possibilidade de conhecer diversas áreas (...)." (Amarílis, BI em Humanidades) 
"(...) teve uma coisa que me encantou no BI foi a possibilidade de eu conseguir, mesmo 'tando' no BI de saúde, eu conseguir fazer algumas disciplinas de C e T, ou pegar alguma de humanidades, que são coisas que eu gosto também além da área de saúde, eu gosto muito de matemática, então essa possibilidade de também estar em uma área que eu gosto e de também pegar um pouco de outras coisas que também me interessam mais, de poder ser interdisciplinar, mas abrangente." (Hortência, BI em Saúde)

A interdisciplinaridade, definida no projeto pedagógico dos BI (UFBA, 2008), como "o estabelecimento de nexos significativos entre os campos disciplinares" (p. 14), também foi considerada decisiva na escolha dos estudantes pelos BI. Segundo dados da pesquisa realizada nos dois semestres do componente curricular Estudos sobre a Contemporaneidade I e II, já mencionada anteriormente, revela que a interdisciplinaridade é valorizada pela possibilidade de integração de conhecimentos e a proposta de modelos pedagógicos mais condizentes com a realidade contemporânea (MAZONI; CUSTÓDIO; SAMPAIO, 2011).

\section{Indecisão quanto à escolha profissional}

Por fim, outro motivo trazido pelos estudantes para escolher os Bacharelados Interdisciplinares foi a questão da indecisão vocacional e a possibilidade de verificar se estão indo pelo caminho correto, se a profissão ou as profissões que almejam são mesmo o que querem. Esse ponto é bem interessante, e destacou-se na pesquisa, pois a metade dos estudantes relatou que passou por dúvidas quanto à profissão que iria seguir no futuro e que o BI o faria ter mais segurança quanto a escolha:

“(...) é eu tinha um norte, não certeza de que era aquilo que eu queria, eu tenho mais certeza agora, mas eu tinha uma direção, um direcionamento, que eu acho que é necessário pra você entrar no BI, você tem que saber pelo menos a área que você quer atuar (...)." (Cerejeira, BI em Ciência e Tecnologia)

"Foi um processo que eu penso em fazer uma das engenharias, porém não tinha certeza de qual... aí escolhi BI, fiz, é uma coisa que vai me esclarecer mais na vida acadêmica, para escolher melhor na frente." (Aro, BI em Ciência e Tecnologia)

“(...) Bem, é, eu não sei a minha área de atuação ainda, eu sei que eu gosto, é sei lá de... desenhar mas eu não sei ainda exatamente como trabalhar com isso (...) acho que o BI, mostrando um leque de possibilidades maior que de outros cursos, eu acho que eu posso enxergar um pouco mais." (Amaranto, BI em Artes)

Outros estudantes afirmaram ter entrado no BI com um curso já definido, no entanto, com o tempo foi se questionando e vislumbrando outras possibilidades:

"Não houve indecisão vocacional, entrei querendo Direito, mas o BI me fez pensar em outras possibilidades, como ser um mestre, um doutor, que vai disseminar conhecimentos na área do Direito." (Aquilégia, BI em Humanidades)

"Minha escolha profissional, ela é um processo que ainda não terminou. Ela está acontecendo e ela às vezes vai para pólos muito opostos, eu sou muito volátil (...) quando criança eu era muito criativo, queria fazer teatro (...) eu tenho pensado muito em letras, porque eu gostei muito de estudar as matérias de letras no BI (...).” (Lisianto, BI em Artes)

"Entrei no BI com o intuito de fazer Medicina, mas agora vejo no BI uma oportunidade diferenciada (...) eu pude conhecer várias áreas (...) A gente fica meio assim, porque eu já não tenho mais certeza, convicção de que realmente é a área, assim continuo com desejo de fazer o curso que desejei inicialmente, mas já não é uma certeza, porque o BI já me possibilitou ter incerteza quanto a isso (...) várias opções pra escolher e questões que a gente pode passear, a gente pode conhecer e diferenciar nos conhecendo, um autoconhecimento (...).” (Allium, BI em Saúde)

Esses discursos revelam a importância de um tempo maior para amadurecer a escolha profissional e encontrar a vocação. Os BI podem auxiliar nesse sentido, não só pelo tempo de três anos que o estudante tem até precisar se direcionar para uma profissão se assim o queira, mas também pelo contato com as várias áreas do conhecimento, que possibilita pensar e experimentar outras possibilidades. Isso é um aspecto bastante inovador dos Bacharelados Interdisciplinares, como se observa nos relatos:

"A princípio eu não tinha, eu tinha a idéia de pesquisar... mas depois eu optei por Medicina. Eu sabia que eu queria fazer pesquisa na área de saúde, mas não tinha um curso certo pra isso, eu só decidi depois que estava no BI.” (Margarida, BI em Saúde)

“(...) Se eu gosto de humanas eu vou pra Direito, porque é isso que o roteiro diz... só que depois eu descobri que Direito não era a minha praia... e vim pro BI de corpo aberto (...) e pretendo sair do Bi pra fazer um mestrado, porque o BI já é um curso superior, e tentar um doutorado porque eu quero ser professor." (Coroa imperial, BI em Humanidades)

“(...) Eu acabei mudando, ao invés de interpretação teatral, eu vi que eu gosto de ensinar, então eu quero fazer licenciatura em teatro (....)." (Flor-de-lis, BI em Artes) 
“(...) Eu entrei na universidade com o intuito de fazer BI de Saúde, mas com o tempo vi que não era o que eu queria e fiz transferência interna para o BI de Humanidades." (Centáurea, BI em Humanidades)

Uma pesquisa realizada no município de Caxias do Sul, no Rio Grande do Sul, com 655 estudantes de 23 diferentes cursos de graduação e instituições de ensino superior (IES) do primeiro ano, investigou em uma de suas questões, a realização pessoal, aptidão e vocação para determinado curso ou profissão. Essa questão foi a que recebeu a melhor média de respostas (379 estudantes), que consideraram esses fatores muito importantes para a sua decisão por um curso superior ou profissão (LUCCHIARI; BONNEAUD, 2006).

Outro aspecto inovador dos BI é que ele traz a escolha vocacional/profissional, antes realizada fora da universidade, para dentro dela.

Por levar em conta essa questão, o projeto político pedagógico dos BI (UFBA, 2008) previa em sua estrutura curricular o eixo orientação profissional, com o intuito de orientar os estudantes na escolha da área de concentração no curso de BI, bem como em estudos posteriores no planejamento e desenvolvimento de sua possível carreira profissional.

No entanto, segundo Matos (2013), essa proposta de orientação está ligada a uma tradição disciplinar, pois o foco é na profissionalização, no direcionamento do estudante ao mundo do trabalho. Portanto, surge, em 2010, um novo posicionamento institucional, que desloca o olhar antes centrado somente na carreira profissional, para uma perspectiva mais próxima da pedagogia da afiliação discutida por Coulon (2008).

\section{CONSIDERAÇÕES FINAIS}

Mediante a pesquisa feita com os estudantes dos Bacharelados Interdisciplinares da UFBA, para averiguar os fatores predominantes na escolha pelos referidos cursos, pode-se detectar diversos fatores, que foram agrupados em uma categoria e três subcategorias de análise. A primeira questão a destacar, é que houve uma diferença nesses fatores nas quatro modalidades de BI: Artes, Ciência e Tecnologia, Humanidades e Saúde.

No que se refere a categoria motivos da escolha pelos BI, os estudantes do BI de Humanidades e Artes demonstraram como fatores predominante na escolha pelos cursos a indecisão vocacional e o interesse em fazer um curso de CPL na área do BI escolhido, após a sua conclusão. Já nos BI de Saúde e de Humanidades, predominou o fator interesse em ingressar nos CPL de Medicina e Direito, respectivamente, o que mostra a predominância do interesse de jovens ingressantes nos $\mathrm{BI}$, pelos cursos de maior prestígio social. A expectativa de ascensão social por meio desses cursos esteve presente nas falas dos estudantes.

A interdisciplinaridade foi outro fator mencionado como um motivo relevante na escolha pelos BI.

É interessante colocar aqui que o estudante que ingressa em um curso de CPL tradicional, sai formado um profissional técnico em alguma área do conhecimento, e normalmente já sabe o que quer fazer e não utiliza o curso como passagem para outro curso. Já nos BI, os estudantes podem utilizar o curso como passagem ou alternativa de ingresso em outros cursos de graduação, ou simplesmente seguir sua formação universitária sem uma finalidade profissionalizante, bem como pode ingressar no mercado de trabalho não como um técnico especializado, mas como um bacharel que atua de forma interdisciplinar em vários contextos. Esse aspecto configura os BI como uma das maiores inovações no ensino superior brasileiro.

Com relação à indecisão vocacional, ou seja, o não saber o que fazer ou que curso de CPL seguir após o término dos BI, foi um aspecto que chamou a atenção nos relatos, o que demonstra uma busca vocacional, e o BI visto como uma possibilidade de adiar uma escolha vocacional/profissional até amadurecê-la. Isso mostra a importância dos BI ao oferecer um tempo aos jovens para amadurecerem seu conhecimento sobre os cursos, as áreas do conhecimento e assim traçarem de forma mais segura e consciente sua trajetória profissional, o que pode contribuir para uma diminuição do abandono no ensino superior, sem contar que os BI surgiram com a proposta de resgatar o verdadeiro papel da universidade que é formar cidadãos, que é contribuir para a transformação social, para a vida, e não só formar bons técnicos, como relataram alguns estudantes na pesquisa. A universidade é um espaço de reflexão, de produção de conhecimento e de produção de novas perspectivas, novas realidades.

Os Bacharelados Interdisciplinares trazem para dentro da universidade uma escolha que antes se dava fora, o que também implica em novos desafios a Universidade Federal da Bahia, bem como a psicologia vocacional. Percebe-se que tem sido cada vez mais frequente a presença de psicólogos atuando em instituições de ensino superior. Quanto aos fatores que influenciam na escolha vocacional/profissional, estão presentes tanto fatores intrínsecos ao indivíduo quanto extrínsecos. Ao escolher um curso universitário, o jovem se depara com uma série desses fatores, e ao escolher o BI, não é muito diferente, apesar desse curso não ter como objetivo a profissionalização, ele permite a permanência da busca vocacional. 


\section{REFERÊNCIAS}

ALMEIDA FILHO, N. A. Memorial da Universidade Nova. 2010. Obra completa no site Scribd. Disponível em: $<$ http:// pt.scribd.com/doc/50945357/Memorial-da-UniversidadeNova>. Acesso em: 23 mar. 2015.

ANDRADE, J. B. A evasão nos Bacharelados Interdisciplinares da UFBA: um estudo de caso. 2014. 179 f. Dissertação (Mestrado em Estudos Interdisciplinares sobre a Universidade) - Programa de Pós-Graduação em Estudos Interdisciplinares sobre a Universidade, Instituto de Humanidades, Artes e Ciências, Universidade Federal da Bahia, Salvador, 2014.

BARDAGI, M. P.; LASSANCE, M. C. P.; PARADISO, A. C. Trajetória acadêmica e satisfação com a escolha profissional de universitários em meio de curso. Rev. Bras. Orientac. Prof., São Paulo, v. 4, n. 1/2, p. 153-166, 2003.

BOCK, A. M. B. Psicologia sócio-histórica. São Paulo: Cortez, 2001

BOHOSLAVSKY, R. Orientação vocacional: a estratégia clínica. 12. ed. São Paulo: Martins Fontes, 2003.

CAMARGO, M. S. de. et al. Referenciais orientadores para os Bacharelados Interdisciplinares e similares. 2010. Disponível em: <http://reuni.mec.gov.br/images/stories/pdf/ novo $\% 20-\% 20$ bacharelados $\% 20$ interdisciplinares $\% 20-\% 20$ referenciais $\% 20$ orientadores $\% 20 \% 20$ novembro_2010\%20 brasilia.pdf>. Acesso em: 18 fev. 2015.

COULON, A. A condição de estudante: a entrada na vida universitária. Salvador: EDUFBA, 2008.

ISASA, M. E. A vocação nossa de cada dia. Belo Horizonte: Nova Acrópole, 2010.

LiMA, L. C.; AZEVEDO, M. L. N.; CATANI, A. M. C. O Processo de Bolonha, a avaliação da educação superior e algumas considerações sobre a Universidade Nova. Revista Avaliação, Campinas, SP, v. 13, n. 1, p. 7-36, mar. 2008.

LUCCHIARI, D. H. P. S.; BONNEAUD, A.-L. Le genoprofessiogramme et le choix de la profession. Rev. Bras. Orientac. Prof., São Paulo, v. 7, n. 1, p. 57-64, 2006.

MACEDO, R. Seu diploma, sua prancha: como escolher a profissão e surfar no mercado de trabalho. São Paulo: Saraiva, 1998.

MATOS, R. da L. A orientação acadêmica entre a disciplinaridade e a interdisciplinaridade. In: SANTOS, G. G. dos;
SAMPAIO, S. M. R. Observatório da vida estudantil: universidade, responsabilidade social e juventude. Salvador: EDUFBA, 2013. p. 121-141.

MAZONI, I.; CUSTÓDIO, L.; SAMPAIO, S. M. R. O Bacharelado Interdisciplinar da Universidade Federal da Bahia. O que dizem os estudantes? In: SAMPAIO, S. M. R. (Org.). Observatório da vida estudantil: primeiros estudos. Salvador: EDUFBA, 2011. p. 229-248.

MÜLLER, M. Orientação vocacional: contribuições clínicas e educacionais. Porto Alegre: Artes Médicas, 1988.

PHILLIPS, N.; HARDY, C. Discourse analysis. Investigating processes of social construction. California: Sage Publications, 2002

RIVELIS, G. Construcción vocacional: carrera o camino? Buenos Aires: Centro de Publicaciones Educativas y Material Didáctico, 2011.

SAMPAIO, S. M. R. et al. Nova universidade, novos estudantes: quem são e o que esperam os estudantes dos Bacharelados Interdisciplinares da Universidade Federal da Bahia. In: SANTOS, G. G. dos; SAMPAIO, S. M. R. Observatório da vida estudantil: universidade, responsabilidade social e juventude. Salvador: EDUFBA, 2013. p. 239-254.

UNIVERSIDADE FEDERAL DA BAHIA - UFBA. Projeto pedagógico dos Bacharelados Interdisciplinares. 2008. Disponível em: <http://cacetufba.files.wordpress.com/2009/10/ projetobicompleto.pdf $>$. Acesso em: 23 mar. 2015.

VÉRAS, R. M. Práticas institucionais/discursivas acerca dos cuidados com os bebês prematuros e/ou de baixo peso: o Programa Canguru. 2010. 223 f. Tese (Doutorado em Psicologia Social) - Programa de Pós-Graduação em Psicologia Social, Centro de Ciências Humanas, Letras e Artes, Universidade Federal do Rio Grande do Norte, Natal, 2010.

VERAS, R. M.; LEMOS, D. V. S.; MACEDO, B. T. F. A trajetória da criação dos bacharelados interdisciplinares na Universidade Federal da Bahia. Avaliação, Campinas, v. 20, n. 3, 2015 .

WILLIG, C. Introducing qualitative research in psychology. Adventures in theory and method. Buckingham: Open University Press, 2001.

Recebido em 07.10.2015

Aprovado em 03.06.2016 